\title{
Conhecimentos declarativos técnico-táticos de handebol manifestados por estudantes em aulas de Educação Física
}

\author{
Talita Fabiana Roque Silva' \\ Lílian Aparecida Ferreira ${ }^{2}$ \\ Carlos Eduardo Lopes Verardi ${ }^{3}$
}

\section{RESUMO}

Os objetivos deste estudo foram identificar e analisar os conhecimentos declarativos técnico-táticos de handebol manifestados por estudantes quando observam e analisam jogos de handebol. O estudo, assentado na abordagem qualitativa, utilizou entrevista e observações de aula para a coleta dos dados. Os participantes foram 30 estudantes de uma turma de sexto ano. Os resultados demonstraram uma série de manifestações de conhecimentos declarativos técnico-táticos do handebol, como o conhecimento das regras básicas necessárias para jogar; o entendimento da dinâmica do jogo (posicionamento em quadra) e a compreensão do jogo oficial da modalidade. Assim, foi possível verificar que os estudantes acessaram, mobilizaram e manifestaram o conhecimento declarativo técnico-tático acerca do handebol, dentre esses conhecimentos: o conhecimento das regras básicas (que dão a possibilidade de conseguir jogar); os objetivos do jogo necessários para o entendimento de seu funcionamento; as características especificas do handebol, bem como aquelas que podem ser transferidas para outros esportes.

Palavras-chave: Conhecimento declarativo. Handebol. Educação física.

1 Docente da rede estadual de ensino de São Paulo e do curso de Educação Física e Fisioterapia da Faculdade Marechal Rondon (FMR). Botucatu/São Paulo, Brasil. E-mail: talitafabianaef@gmail.com

2 Docente da Faculdade de Ciências, Departamento de Educação Física e pós-graduação em Docência para a Educação Básica da Universidade Estadual Paulista Júlio de Mesquita Filho (UNESP). Bauru/São Paulo, Brasil. E-mail: lilibau@fc.unesp.br

3 Docente da Faculdade de Ciências, Departamento de Educação Física da Universidade Estadual Paulista Júlio de Mesquita Filho (UNESP). Bauru/São Paulo, Brasil. E-mail: verardi@fc.unesp.br

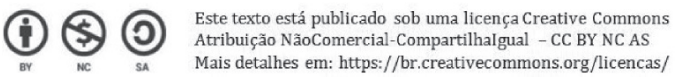


Technical-tactical declarative knowledge of handball expressed by students in Physical Education classes

\begin{abstract}
The objectives of this study were to identify and analyze the technical-tactical declarative knowledge of handball expressed by students when observing and analyzing handball games. The study, based on the qualitative approach, used interview and class observations to collect the data. The participants were thirty students from a sixth grade class. The results demonstrated a series of declarations of technical-tactical declarative knowledge of handball, such as knowledge of the basic rules necessary to play; the understanding of the dynamics of the game (positioning on the court) and the understanding of the official game of the modality. Thus, it was possible to verify that the students accessed and mobilized the declarative technical-tactical knowledge about handball, among these knowledge: knowledge of the basic rules (which give the possibility of being able to play); the objectives of the game necessary for the understanding of its functioning; the specific characteristics of handball, as well as those that may be transferable to other sports.
\end{abstract}

Keywords: Declarative knowledge. Handball. Physical education.

\title{
Conocimientos declarativos técnico-tácticos de balonmano manifestados por estudiantes en clases de Educación Física
}

\section{RESUMEN}

Los objetivos de este estudio fueron identificar y analizar los conocimientos declarativos técnico-tácticos de balonmano manifestados por estudiantes cuando observan y analizan juegos de balonmano. El estudio, asentado en el abordaje cualitativo, utilizó entrevista y observaciones de clase para la recolección de los datos. Los participantes fueron treinta estudiantes de una clase de sexto año. Los resultados demostraron una serie de manifestaciones de conocimientos declarativos técnico-tácticos del balonmano, como el conocimiento de las reglas básicas necesarias para jugar; el entendimiento de la dinámica del juego (posicionamiento en cuadra) y la comprensión del juego oficial de la modalidad. Así, fue posible verificar que los estudiantes accedieron y movilizaron el conocimiento declarativo técnico-táctico acerca del balonmano, entre esos conocimientos: el conocimiento de las reglas básicas (que dan la posibilidad de conseguir jugar); los objetivos del juego necesarios para el entendimiento de su funcionamiento; las características específicas del balonmano, así como las que pueden ser transferibles para otros deportes.

Palabras clave: Conocimiento declarativo. Balonmano. Educación física. 


\section{INTRODUÇÃO}

O esporte exerce um papel de significativa influência dentro das aulas de Educação Física, e não poderia ser diferente, visto que, o mesmo se apresenta como fenômeno mundial se fazendo presente nas mídias, na economia, na política e na cultura das pessoas. Além disso, o esporte é considerado, em muitos momentos, como sinônimo da Educação Física no ambiente escolar, isto porque ele é muito presente nas aulas, ofuscando outras manifestações da cultura corporal de movimento. Entretanto, apesar deste cenário relativo de poder do esporte na escola, não são poucas as discussões sobre a exclusão ou manutenção do mesmo nas aulas de Educação Física, até porque ele reinou por muito tempo como hegemônico na Educação Física em prol da identificação de talentos esportivos e formação de atletas (BRACHT, 1992).

Pensar que a escola é um local rico para a construção de novos conhecimentos, o que não deveria ser diferente para os esportes, é defender que podemos criar nossas próprias práticas esportivas articuladas com as outras já existentes. Sendo assim, não defendemos a exclusão do esporte oficial do meio escolar, mas sim que ele seja ensinado com caráter educativo, no qual o estudante possa construir, mediado pelo professor, uma interlocução crítica e autônoma das relações do esporte com a sua vida.

Reconhecemos as diversas possibilidades de análise do esporte como conteúdo da Educação Física escolar, entretanto, a ênfase deste nosso texto se dará, mais especificamente, tematizando o conhecimento declarativo, sem desprezar ou desconsiderar, contudo, os conhecimentos que são construídos no/pelo próprio corpo. Para além deste conhecimento corporal, ao se ensinar o conteúdo esporte na escola, há uma mobilização da atividade mental dos estudantes, um tipo de elaboração que transita no campo das caracterizações estruturais e funcionais impostas pela dinâmica de cada esporte. Por exemplo, ao se jogar handebol em uma aula, os estudantes interagem com suas regras, com as limitações específicas estabelecidas pelo espaço, com seus colegas de equipe, com os adversários e, principalmente, com as buscas para resolver os desafios impostos pelo próprio esporte. A materialização desta atividade mental, em formato de conhecimento declarativo, ou seja, transpor as percepções do pensamento para a fala e a escrita pode possibilitar uma ampliação dos recursos pedagógicos para as aulas de Educação Física, permitindo que sejam acessados outras formas de conhecer o esporte e que contribuam com a própria melhoria da forma de jogar o esporte por parte dos estudantes.

Ainda assim, concordamos com Dietrich, Dürrwächter e Schaller (1984) quando defendem que jogar se aprende jogando e, neste sentido, a contribuição do ensino do conteúdo esporte nas aulas de Educação Física, envolvendo também o conhecimento declarativo dos estudantes com relação ao esporte, se daria com o propósito de ampliar as possibilidades de aprendizagem e não de limitá-las.

Com base nestas perspectivas, os objetivos do presente estudo foram identificar e analisar os conhecimentos declarativos técnico-táticos do handebol manifestados por estudante quando observam e analisam jogos da referida modalidade. 


\section{Revisão da literatura}

Para Vago (1996), sendo o esporte um dos conteúdos a serem trabalhados nas aulas de Educação Física na escola, ele deveria deixar de ser uma negação radical para assumir uma relação de tensão permanente, ou seja, ao invés de se reproduzir as práticas esportivas determinadas por outros meios que não a escola, deveria ser ensinado assentado em uma dinâmica que desse condições para o estudante intervir de modo autônomo e crítico na sociedade em que vive.

Dentro dos esportes, podemos trabalhar com diversos tipos de conhecimentos, sendo um deles os conhecimentos técnico-táticos. Segundo Gonzalez e Bracht (2012), dentre estes acessos seria possível, por exemplo, identificar

[...] como se classificam os esportes de acordo com os princípios táticos, as demandas orgânicas geradas por diferentes modalidades, mas também por conhecimentos vinculados à modalidade (o que se cobra e como se dá continuidade a uma partida após uma falta) e à gestão do jogo (forma como se preenche uma súmula). (p.57)

Ainda concordando com os mesmos autores, o conhecimento técnico-tático pode auxiliar em um entendimento melhor sobre o desenvolvimento dos esportes, estando intimamente ligado às descrições permitidas pelas análises da lógica interna ${ }^{4}$, bem como auxiliando no entendimento ampliado do fenômeno esportivo que pode ser desenvolvido a partir dos seguintes pontos:

- Conceito de esporte;

- Transformação de jogos em esporte;

- Lógica interna e externa;

- Categorias e tipos de esportes;

- Regras esportivas;

- Elementos de desempenho esportivo;

- Relação entre categorias de esportes e demandas dos elementos de desempenho esportivo;

- Papéis (subpapéis) dos jogos nos diferentes tipos de esportes;

- Nomenclatura e características das técnicas dos diferentes tipos de esporte e nomenclatura e características das intenções tática, combinações táticas e sistemas de jogo das modalidades com interação entre adversários;

- Atores do esporte institucionalizado: técnico, árbitro, dirigente;

- Avaliação e orientação do desempenho esportivo;

- Condução e organização de equipes durante uma competição;

- - Arbitragem de modalidades esportivas;

4 Lógica interna significa, segundo Parlebas (2001, p. 302) “[...] o sistema de características próprias de uma situação motora e das consequências que esta situação demanda para a realização de uma ação motora correspondente". Ou seja, a lógica interna está diretamente ligada ao sistema de obrigações imposto pelas regras do jogo, isto é, dos limites a serem respeitados para que se possa participar do mesmo (PARLEBAS, 2001). 
- Auxílio na arbitragem de modalidades esportivas;

- Organização clássica e alternativa de torneios e campeonatos. (GONZALEZ; BRACHT, 2012, p. 57)

Com esse cenário apresentado ainda são necessários, no entanto, muitos avanços teóricos e didático-pedagógicos que colaborem para compreender o esporte num sentido muito além de mera prática, ou seja, como um fenômeno sócio-histórico-cultural em que a Educação Física escolar produza a aquisição de um saber fazer e um saber sobre esse fazer do esporte (CARLAN, KUNZ e FENSTERSEIFER, 2012).

Partindo deste ponto de vista e considerando o que propõe Sternberg (2000), o conhecimento pode ser dividido em dois tipos: conhecimento declarativo e conhecimento processual. Para os profissionais da Educação Física, o conhecimento processual está mais próximo, visto que está ligado aos aspectos práticos/vivenciais da atividade, já o conhecimento declarativo está mais voltado para explicar, narrar, como um fato se constitui.

Para Antunes e Dantas (2010), o conhecimento declarativo na Educação Física pode ser encontrado tanto nas dicas essenciais para a execução de uma habilidade motora, como no significado sociocultural de uma determinada prática corporal, ou ainda nas orientações sobre o gasto energético a ser despendido num certo exercício físico. Já o conhecimento declarativo técnico-tático refere-se ao que o jogador tem estruturado na forma de representações mentais, permitindo-lhe relacionar os diferentes conceitos que constituem o conjunto de conhecimentos sobre o regulamento, estratégias, táticas ofensivas e defensivas, assim como das diferentes posições dos jogadores na quadra, suas funções e como agir nas diferentes situações (MORALES; GRECO, 2007).

Dentro de um jogo esportivo, a atuação do jogador está intimamente ligada aos conhecimentos declarativo e processual. Tais conhecimentos orientam as decisões dos jogadores, condicionando-os à organização da percepção, à compreensão das informações e à atitude motora (GRECO, 2006). Assim, quando um estudante realiza uma técnica específica de um esporte de oposição e cooperação simultâneas ${ }^{5}$, por exemplo o handebol, ele toma uma decisão tática escolhendo a ação motora mais adequada para resolver a situação e, nesse caso, o conhecimento declarativo e processual estão interligados na busca pelos objetivos do jogo (SILVA e GRECO, 2009).

Com base nestes pressupostos, compreender o jogo implica, para quem joga, "saber o que fazer" em determinada situação, relacionando a experiência corporal com informações, conceitos e conhecimentos específicos, ou seja, com um conhecimento declarativo que amplie suas possibilidades para responder a determinada situação imposta pelo jogo esportivo.

5 Segundo Parlebas (2001), os esportes de oposição e cooperação simultâneas são atividades nas quais os sujeitos colaboram/cooperam com seus companheiros de equipe e, simultaneamente, se enfrentam/opõem diretamente com a equipe adversária. Nessa relação de oposição e cooperação, uma equipe tenta, em cada ato, atingir os objetivos do jogo, ao mesmo tempo em que tenta impedir que os adversários o façam. 


\section{METODOLOGIA}

O delineamento metodológico escolhido para o estudo foi a pesquisa qualitativa, por entender que "[...] ela trabalha com o universo de significados, motivos, aspirações, crenças, valores e atitudes, o que corresponde a um espaço mais profundo das relações, dos processos e dos fenômenos [...]" (MINAYO, 2002, p. 21). Para Sampieri, Collado e Lucio (2013) esse tipo de pesquisa possibilita descrever, compreender e interpretar os fenômenos, por meio das percepções e dos significados produzidos pelas experiências dos participantes.

Refletir sobre as ações dentro do ambiente escolar não é o bastante para resolver as dificuldades encontradas no dia-a-dia, mas sim é necessário pensar, agir e refletir sobre os fatos. Então a pesquisa-ação (CHIZZOTTI, 2010) se mostrou adequada ao estudo em questão.

A intervenção constituiu-se de aulas de Educação Física, com um total de onze semanas, uma vez que a pesquisadora era também a professora de Educação Física da turma pesquisada. Utilizamos para a coleta de dados, as observações das aulas (registradas em diários de aula pela pesquisadora) e os questionários respondidos pelos estudantes, a partir das fichas e roteiros de observações.

Os participantes foram 30 estudantes, de uma turma de sexto ano do ensino fundamental, com idade entre 10 e 12 anos, sendo 13 meninas e 17 meninos. A escolha pela turma se deu de forma aleatória.

Após a coleta dos dados, houve a reunião e organização dos resultados para serem analisados. Foi realizada uma leitura atenta de todo o material, buscando identificar os elementos recorrentes nos registros (da pesquisadora e dos estudantes) relacionados ao objetivo da pesquisa e ao referencial teórico que balizou o estudo.

Seguindo as normas éticas exigidas nas pesquisas com seres humanos, os responsáveis pelos estudantes assinaram o Termo de Consentimento Livre e Esclarecido - TCLE, assim como, os estudantes assinaram o Termo de Assentimento Livre e Esclarecido - TALE. O trabalho foi aprovado pelo comitê de ética da universidade correspondente, com o parecer número 1.460 .813 .

\section{Resultados e discussão}

Concordamos com González e Bracht (2012) quando apontam que para ensinar o esporte é importante identificar as dificuldades iniciais e os conhecimentos prévios dos estudantes. Essa identificação, associada a um processo contínuo de diagnóstico da situação, permite que sejam acessados os avanços em seus desempenhos, os conhecimentos adquiridos anteriormente, as percepções de suas facilidades e dificuldades. Sob este ponto de vista, os estudantes quando questionados inicialmente a respeito do funcionamento do jogo de handebol, manifestaram as respostas que estão apresentadas nos gráficos a seguir. 


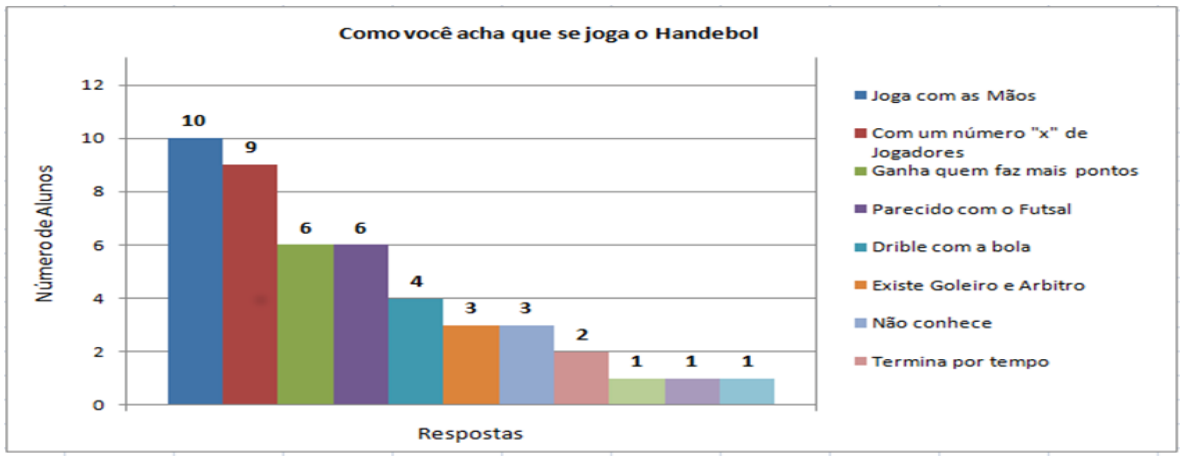

Gráfico 1 - Como você acha que se joga o handebol?

Fonte: Construído a partir das repostas dos estudantes ao questionário da avaliação diagnóstica realizado na primeira semana de aula.

Podemos observar, analisando o gráfico, que os estudantes demonstraram um conhecimento mais estrutural que funcional em relação ao handebol, ou seja, a demarcação de fragmentos do que há no jogo, por si só, não evidencia sua forma de ocorrência, sua dinâmica. Ao apontar sobre o fato de ser jogado com as mãos, possuir um número x de jogadores, de ter goleiro e árbitro, de poder driblar a bola e terminar por tempo são fatores que explicitam os elementos do jogo, mas não em si sua forma de jogar. Neste caso, o que expressa uma lógica funcional é o estabelecimento da semelhança do jogo de handebol com o jogo de futsal, ainda que tenha se dado sem maiores detalhamentos. Ao fazerem esta aproximação entre o futsal e o handebol os estudantes parecem esboçar que tanto uma modalidade quanto a outra nutrem semelhanças que, segundo Mitchell, Oslin e Griffin (1997) poderiam ser denominados por esportes de invasão.

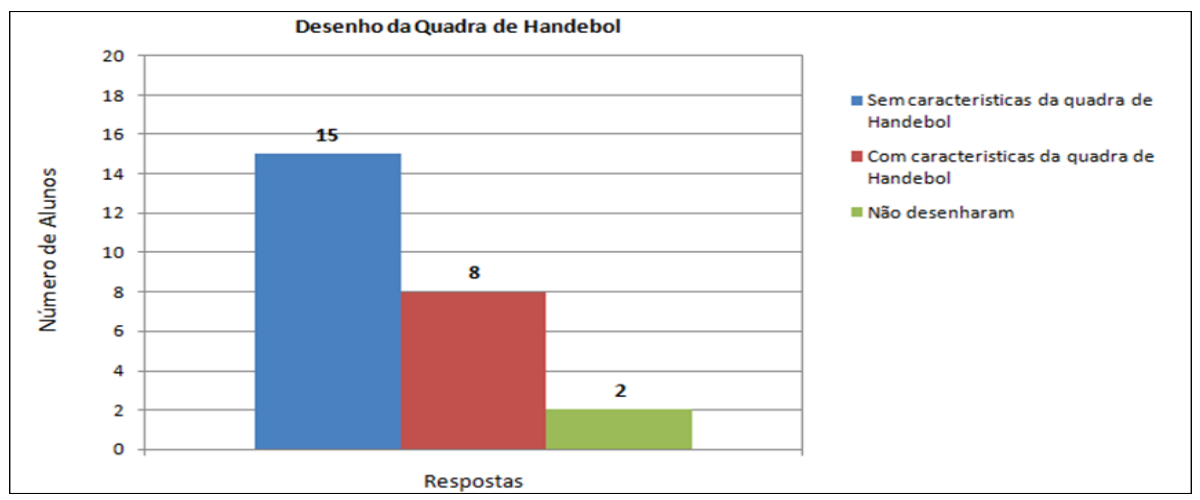

Gráfico 2 - Desenho da quadra de handebol

Fonte: Gráfico construído a partir das repostas dos estudantes ao questionário da avaliação diagnóstica realizada na primeira semana de aula. 
A maioria dos estudantes revelou não ter conhecimento sobre a quadra de handebol, indicado pelas respostas de 15 alunos. Apenas oito estudantes expressaram algum conhecimento ao desenharem a área do goleiro e/ou a linha tracejada. Dois estudantes não se sentiram à vontade nem para desenhá-la, e estes quando questionados sobre isso, disseram que não faziam a mínima ideia de como desenhar a quadra de handebol.

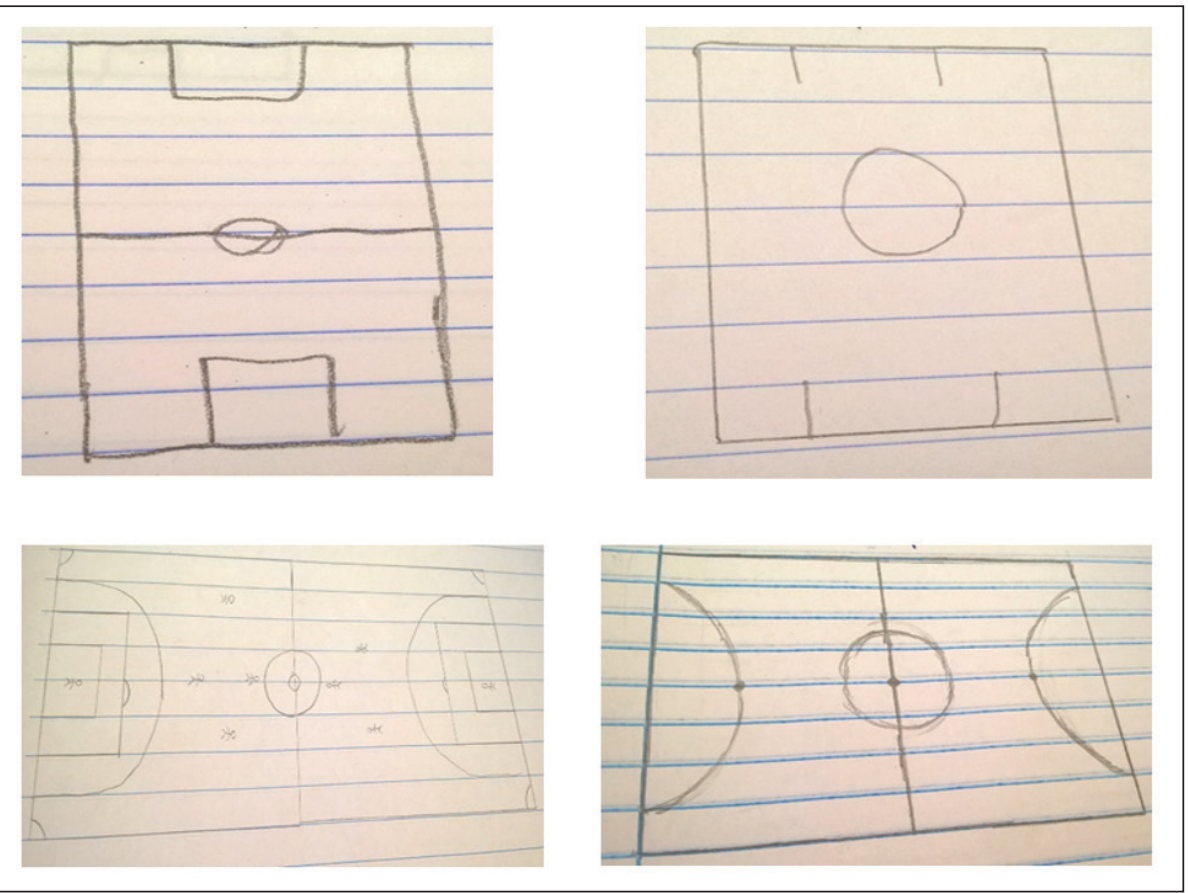

Quadro 1 - Desenho da quadra realizado pelos estudantes Fonte: Material de aula da professora/pesquisadora de Educação Física da turma. Aula diagnóstica, primeira semana.

Nos desenhos desenvolvidos pelos estudantes podemos observar a influência, ou um maior conhecimento/aproximação, com relação à quadra de futsal e o campo de futebol, o que pode ser induzido por uma cultura escolar na qual o futsal é mais presente, bem como de espaços públicos de lazer que possibilitam uma maior prática do futsal quando comparado ao handebol. Além disso, o fato do futebol ter uma presença constante nos espaços midiáticos, parece se estabelecer como referência para os estudantes e, talvez por isso, eles evidenciem este vínculo.

Para Betti (1998), a Educação Física escolar precisa permitir aos estudantes a capacidade de interpretar os textos visuais produzidos pela mídia, principalmente, a linguagem televisiva. "Há a necessidade, em um primeiro momento, de uma imersão completa para 
compreender a mensagem audiovisual, mas é também necessário o segundo tempo, à distância, para chegar a uma certa verdade do conhecimento" (p. 59). Sendo assim, fica evidenciado nas respostas dos estudantes bem como na fala do autor, que a mídia esportiva exerce influência na sociedade, mas que a Educação Física pode contribuir, permitindo que os estudantes façam uma leitura crítica das mensagens midiáticas.

Já quando realizado o primeiro jogo da turma (durante a primeira semana de aula/ pesquisa), quando os estudantes observaram os colegas, foi possível notar que os eles eram bastante rigorosos quando estavam no papel de observadores de seus colegas, sendo exigentes com relação ao cumprimento das regras. Durante a observação do jogo foram muitos comentários "denunciando" as faltas cometidas e as regras desrespeitadas. Algumas falas elucidam estes aspectos:

José tem mania de futebol, e quer parar a bola com o pé. (Joana $)^{6}$

Como não pode tirar a bola da mão do inimigo, fica um monte de gente em cima de quem está com a bola. (José)

As meninas têm dificuldade com as três passadas, para mim elas estão dando mais que isso. (Victor)

Tem gente que não tem paciência e tira a bola da mão do adversário mesmo não podendo, não sabe respeitar o jogo. (Amanda)

Toda hora alguém entra na área do goleiro, parece que não presta atenção. (Pedro) Eles querem ficar perto do gol para fazer o gol, aí acabam entrando na área do goleiro, e quando percebem saem correndo, (risadas). (Gustavo)

Com a observação do primeiro jogo televisivo de handebol feminino (Brasil contra Estados Unidos), realizado na segunda semana de aula/pesquisa, os estudantes conseguiram identificar algumas particularidades da modalidade, que foram captadas pelas suas respostas escritas para a seguinte pergunta: Quais as principais características do jogo?

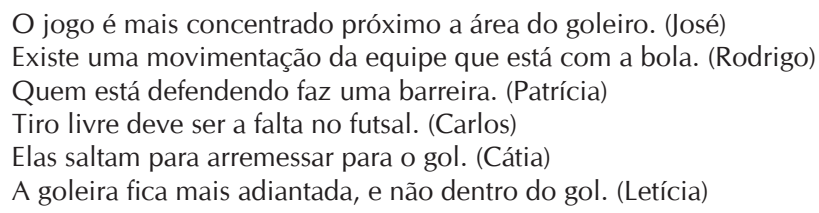

Para Knijinik (2009), o handebol é definido como um jogo de associação com o adversário também chamado de jogo de oposição-cooperação e invasão. A ocupação do espaço é comum a todos os jogadores, exceto as áreas do goleiro. Assim, o jogo ocorre de forma que todos participem simultaneamente, seja atacando ou defendendo. Entretanto, a posse de bola entre os jogadores e as equipes é desigual, ou seja, variável. Nesse sentido, a todo momento a modalidade apresenta desafios à inteligência dos jogadores, ora de

6 Os nomes citados neste texto são fictícios, garantindo o anonimato dos participantes do estudo, entretanto, são identificados o gênero dos mesmos. 
cooperação com os companheiros, ora de confronto com os adversários. Os estudantes, portanto, demonstraram aspectos relacionados ao conhecimento do handebol, como as características do jogo, o que pode ser revelado como um aprendizado acerca da modalidade.

Após oito semanas de aulas envolvendo o conhecimento declarativo no handebol, pudemos observar, como apresentado no gráfico a seguir, uma mudança correspondente à aprendizagem demonstrada pelos estudantes.

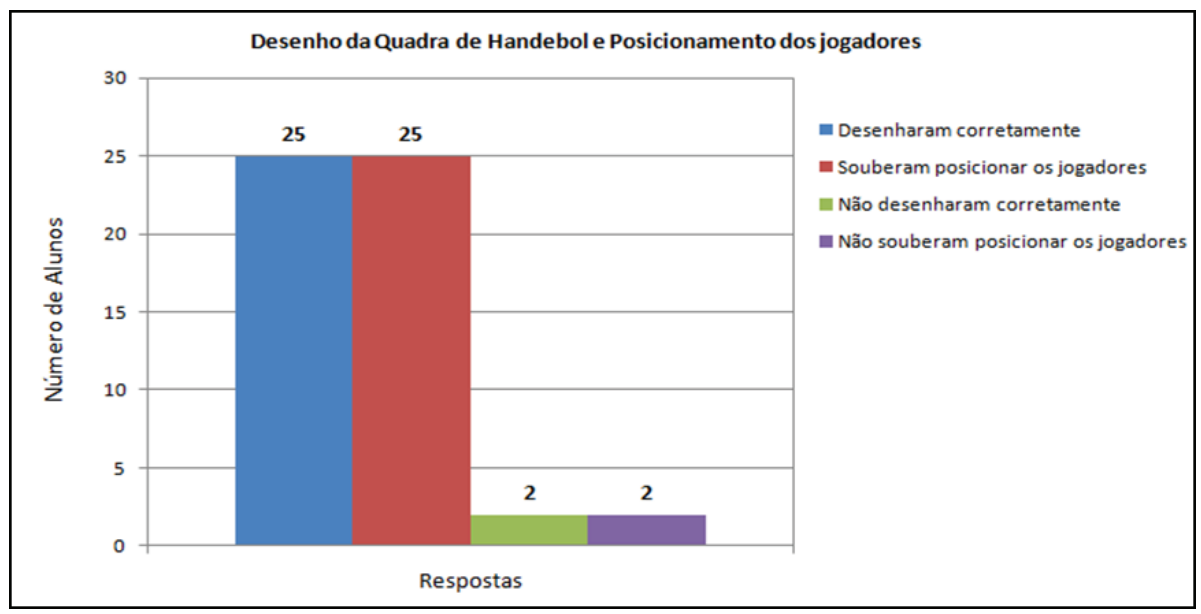

Gráfico 3 - Desenho da quadra de handebol e o posicionamento dos jogadores Fonte: Gráfico construído a partir das respostas dos estudantes ao questionário aplicado na oitava semana de aula.
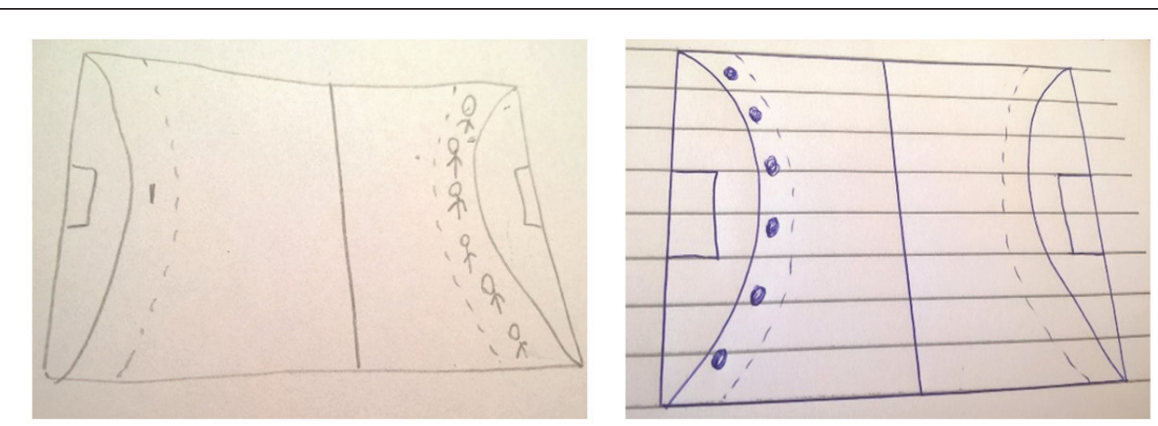

Quadro 2 - Desenho da quadra de handebol

Fonte: Material de aula da professora/pesquisadora de Educação Física da turma.

Desenho dos alunos produzidos na aula da oitava semana. 
Ao compararmos os desenhos dos estudantes realizados na primeira semana de aula e após oito semanas, fica evidente que os estudantes desenvolveram um conhecimento mais elaborado a respeito das características da quadra oficial de handebol. Essa construção foi possível a partir das vivências realizadas em aula, nas quais os estudantes foram apresentados aos elementos que constituíam o jogo de handebol, bem como dos vídeos assistidos por eles em aula.

Acerca da dinâmica de funcionamento do jogo, suas regras e táticas, os resultados identificados foram dividimos em dois blocos: 1. Os conhecimentos a partir de observação de jogos televisivos; 2. Os conhecimentos a partir da observação dos jogos dos colegas de sala.

Quando os estudantes observaram o jogo televisivo de handebol feminino (Brasil $x$ Sérvia) relacionaram alguns aspectos ligados às regras, ao funcionamento do jogo e até mesmo às questões de preconceito, o que pode ser verificado no quadro apresentado a seguir, elaborado com base nas falas dos estudantes enquanto assistiam ao jogo.

Quadro 3 - Aspectos relacionados pelos estudantes durante a observação do jogo

\begin{tabular}{|l|l|}
\hline \multicolumn{2}{|c|}{ Aspectos relacionados pelos alunos: } \\
\hline Falta de ataque & Tiro de 7 metros \\
\hline Jogo passivo & Vale gol de goleiro? \\
\hline Pé na área do goleiro & Questões de preconceito \\
\hline Como funcionam os cartões & O que é o scout? \\
\hline Tiro de canto & Cartão amarelo para o assistente \\
\hline
\end{tabular}

Fonte: Quadro construídos a partir das falas dos estudantes, durante a análise do jogo televisivo assistido na quinta semana de aula.

Os estudantes ficaram bastante atentos aos comentários e às informações que eram disponibilizadas na transmissão do jogo pelo comentarista da televisão.

Eles, assim como o comentarista, utilizaram a palavra escanteio para fazer referência ao tiro de canto; ao tempo de exclusão que ficava visível em um canto da televisão e ao modo como uma jogadora foi chamada (bucha de canhão), de modo que pudéssemos discutir muitas questões ligadas ao jogo.

Para a observação e análise dos jogos dos colegas de sala, utilizamos o instrumento Team Sports Performance Assessment Procedure - TSAP, que se trata de uma das possibilidades de avaliação em Educação Física quando trabalhamos com o conteúdo esporte. Tal instrumento avaliativo, embora possa se constituir como um recurso interessante para a Educação Física escolar, tem sua utilização ainda restritra ao campo investigativo, na área da iniciação esportiva ou do alto rendimento (GONZALEZ; FRAGA, 2012). O TSAP, de acordo com Costa et al. (2010), foi desenvolvido por Gréhaigne, Godbout e Bouthier na década de 1990, como um instrumento para providenciar informações sobre o desempenho dos jogadores no que refere aos comportamentos realizados durante a fase ofensiva do 
jogo. O instrumento é composto de duas dimensões: a posse de bola por passe e a posse de bola por aproveitamento (recuperação). Assim, as dimensões a serem observadas nos jogos coletivos de invasão são 1) posse de bola em ações de bola recebida (passe) ou bola conquistada/recuperada; e 2) aproveitamento da posse de bola em ações de bola perdida (perdida pelo adversário), bola neutra (passe para progressão/circulação de bola), bola ofensiva (passe com possibilidade de gerar ponto) e bola exitosa (com conversão de ponto).

Os estudantes quando questionados a respeito do passe da bola e do aproveitamento da posse de bola, manifestaram as falas a seguir:

Foram muitas bolas perdidas e pouco aproveitadas, já que poderíamos ter roubado a bola, colocado na ofensiva e finalizar, mas quando estou jogando não consigo fazer isso. (Camila)

Eu falo para eles passarem a bola para mim, que estou bem posicionado para jogar para o gol, mas eles não passam, professora. (Lucas)

As outras meninas não conseguem ver o jogo, elas querem se livrar da bola, e aí não chegamos ao gol. (Joana)

São muitas bolas neutras ou perdidas, o que faz o time perder as oportunidades de fazer gol, né. (Alan)

A outra equipe teve várias bolas ofensivas, mas não chegou a ser exitosa, né mesmo professora? (Rodrigo)

Com estas falas dos estudantes foi possível verificar que ocorreu uma apropriação relacionada às demandas do jogo. Relacionar bolas ofensivas, neutras, perdidas e exitosas, requer um bom nível de conhecimento acerca das solicitações demarcadas pelo jogo, o que parece indicar estudantes conhecedores destas características.

As falas dos estudantes também podem demonstrar uma compatibilidade entre o que se ensina e o que se avalia, já que as demandas do jogo eram solicitadas e, em seguida, relatadas por eles.

A aprendizagem dos sistemas táticos defensivos por parte dos estudantes apareceram descritas nos relatos referentes à aula da nona semana. No início das atividades os estudantes não tinham familiaridade com o conteúdo handebol, o que foi verificado com a avaliação diagnóstica da primeira semana. Neste novo momento, a organização em quadra que eles demonstraram, bem como, as palavras por eles utilizadas, evidenciaram essa aprendizagem.

A equipe amarela joga com o sistema $6 \times 0$ e 5x1, dá para perceber isso. (Patrícia) Eu acho que a equipe azul não sabe direito fazer um sistema de defesa. (Rodrigo) Não sei identificar o sistema que eles jogam, mas vejo que eles voltam bastante para defender. (Evandro ${ }^{7}$ )

O jogo está bonito. Não tem mais aquele monte de gente em cima da bola. (Letícia) Eu queria que eles jogassem organizados como os vídeos que assistimos a um tempo atrás. Fica mais bonito. Mas está melhorando. (Cátia)

7 Evandro era um aluno que tinha ingressado na escola depois do trabalho com o conhecimento declarativo técnico-tático ter sido iniciado. 
Eu acho o jogo eficiente porque tão fazendo gol. (Leandro)

Segundo o que aprendemos, o jogo é eficiente quando a bola passa nas mãos dos colegas de maneira rápida e com objetivo de chegar no gol e acertar ele, é claro, então acho que está meio eficiente. (José)

É eficiente porque não é mais aquele jogo parado, que ficamos contando os passos com a bola nas mãos. (Joana)

Uma outra possibilidade de construção e de demonstração do conhecimento declarativo, foi a vivência e atuação dos estudantes como árbitros nos jogos da própria turma. Para realizar essa atividade foi necessário desenvolver com os estudantes o conhecimento das regras básicas. Na décima primeira semana de aula, os estudantes arbitraram os jogos da própria turma com atitudes muito respeitosas entre eles. Foram jogos disputados e, de maneira geral, com os árbitros bem atuantes. Os estudantes queriam, de fato, atuar no jogo. Eles agiam com certo nervosismo, mas de maneira bem efetiva e em toda infração faziam algum tipo de sinalização interrompendo o jogo para explicar aos colegas o ocorrido.

Ao final de todos os jogos fizemos uma roda de conversa para que eles falassem a respeito da sensação de atuar como árbitro do jogo.

Eu fiquei meio com medo no começo, mas depois gostei. (Lúcio)

Precisa prestar muita atenção no jogo, porque é difícil ver tudo. (Neide)

Parece que você quer que o colega erre para você apitar. (risadas) (Victor)

Eu apitei um tiro de sete metros, mas acho que não foi. (risadas) (Valéria)

Eu gostei muito de apitar, acho que levo jeito. (Carlos)

Você precisa ter todas as regras na cabeça para não fazer besteira. (Everton)

A gente poderia fazer assim com todos os esportes né pro? (Letícia)

Eu fiquei preocupada com as regras e não consegui olhar para o jogo de maneira ampla como você fala pra gente fazer. (Alice)

No decorrer da discussão destes apontamentos, foi possível verificar que os estudantes acessaram, mobilizaram e manifestaram o conhecimento declarativo técnico-tático acerca da modalidade handebol. Dentre esses conhecimentos, podemos citar o conhecimento das regras básicas (que dão a possibilidade de conseguir jogar); os objetivos do jogo necessários para o entendimento de seu funcionamento; as características especificas do handebol, bem como aquelas que podem ser transferíveis para outros esportes.

\section{CONCLUSÕES}

Com base nos objetivos deste estudo, que foram: identificar e analisar os conhecimentos declarativos técnico-táticos de handebol manifestados por estudantes quando observam e analisam jogos de handebol (de seus colegas de sala e de vídeos utilizados pela pesquisadora/professora de Educação Física da turma), nos foi possível identificar uma série de manifestações de conhecimentos declarativos técnico-táticos do handebol por parte dos estudantes, a saber: o conhecimento das regras básicas necessárias para jogar; 
o entendimento da dinâmica do jogo (posicionamento em quadra) e o entendimento de um jogo oficial.

Nosso estudo evidenciou que o desenvolvimento do conhecimento declarativo nas aulas de Educação Física contribui para a ampliar o conhecimento dos estudantes acerca do conteúdo esporte, ou seja, se materializa como um recurso a mais para as aulas de Educação Física. Neste caso, o desenvolvimento da experiência corporal associado com o conhecimento declarativo nas aulas de Educação Física pode significar novas possibilidades de aprendizagem para os estudantes.

Vale ressaltar, que ainda necessitamos de mais pesquisas com essa temática para dialogarmos com outros resultados e, possivelmente, contribuirmos com a reconfiguração de outras formas de se pensar e se fazer Educação Física na escola.

\section{REFERÊNCIAS}

ANTUNES, Fabia Helena Chiorboli; DANTAS, Luiz. Sistematização do conhecimento declarativo em educação física escolar de $5^{\mathrm{a}}$ à $8^{\mathrm{a}}$ séries do ensino fundamental. Revista Brasileira de Educação Física e Esporte, [s.I.], v. 24, n. 2, p.205-221, jun. 2010. FapUNIFESP (SciELO). http://dx.doi.org/10.1590/s1807-55092010000200005.

BETTI, Mauro. Janela de Vidro: esporte, televisão e educação física. Campinas: Papirus, 1998.

BRACHT, Valter. Aprendizagem social e educação física. Porto Alegre: Magister, 1992.

CHI, Michelene.; GLASER, Robert. Capacidade para a Solução de Problemas. In: STEMBERG, Robert J. As Capacidades Intelectuais Humanas: uma abordagem em processamento de informações. Porto Alegre: Artes Médicas. p. 250-275, 1992.

CHIZZOTTI, Antonio. Pesquisa qualitativa em ciências humanas e sociais. Rio de Janeiro: Vozes, 2010.

COSTA, Israel Teoldo et al. Análise e avaliação do comportamento tático no futebol. Revista da Educação Física/UEM, v. 21, n. 3, p.443-455, 31 jul. 2010. Universidade Estadual de Maringa. http://dx.doi.org/10.4025/reveducfis.v21i3.8515. Disponível em: < http:// www.periodicos.uem.br/ojs/index.php/RevEducFis/index > . Acesso em: 18 set. 2016.

COSTA, Luciane Cristina Arantes da; NASCIMENTO, Juarez Vieira do. O ensino da técnica e da tática: novas abordagens metodológicas. Revista da Educação Física/UEM, Maringá, v. 15, n. 2, p.49-56, 2004. Contínua. Disponível em: < http://www.periodicos.uem. br/ojs/index.php/RevEducFis/index >. Acesso em: 10 abr. 2016.

EYSENCK, Michael W.; KEANE, Mark T. Psicologia cognitiva: um manual introdutório. Porto Alegre: Artmed, 1994. 490 p.

FREIRE, Paulo. Pedagogia da autonomia: saberes necessários à prática educativa. São Paulo: Paz e Terra, 2002. 54 p.

GONZÁLEZ, Fernando Jaime; BRACHT, Valter. Metodologia dos Esportes Coletivos. Vitória: UFES: Núcleo de Educação Aberta e a Distância, 2012. 126 p. 
GONZÁLEZ, Fernando Jaime; FRAGA, Alex Branco. Afazeres da educação física na escola: planejar, ensinar, partilhar. Erechim: Edelbra, 2012. 208 p.

GRECO, Pablo Juan (Org.). Iniciação esportiva universal: metodologia da iniciação esportiva na escola e no clube. Belo Horizonte: Ufmg, 1998.

GRECO, Pablo Juan. Conhecimento tático-técnico: eixo pendular da ação tática (criativa) nos jogos esportivos coletivos. Revista Brasileira de Educação Física e Esporte, São Paulo, v. 20, p.210-212, set. 2006. Suplemento 5. Disponível em: < http://citrus.uspnet.usp.br/ eef/uploads/arquivo/v\%2020\%20supl5\%20artigo55.pdf > . Acesso em: 10 maio 2016.

HERRERO, Juan Antonio García. Entrenamiento en balonmano. Bases de la construcción de un proyecto de formación defensiva. Barcelona: Paidotribo, 2003. 342 p.

KNIJNIK, Jorge Dorfman. Handebol: Agôn: o espírito do esporte. São Paulo: Odysseus, 2009. $213 \mathrm{p}$.

LUCKESI, Cipriano Carlos. Avaliação da aprendizagem escolar. São Paulo: Cortez, 2000. MINAYO, Maria Cecília Souza de (Org.). Pesquisa social: teoria, método e criatividade. 34. ed. Petrópolis: Vozes, 2002. 112 p.

MITCHELL, Stephen A.; OSLIN, Judith L.; GRIFFIN, Linda. Teaching Sport Concepts and Skills: a tactical games approach for ages 7 to 18. United States: Human Kinetics, 1997. MORALES, Juan Carlos Pérez; GRECO, Pablo Juan. A influência de diferentes metodologias de ensino-aprendizagem-treinamento no basquetebol sobre o nível de conhecimento tático processual. Revista Brasileira de Educação Física e Esporte, São Paulo, v. 21, n. 4, p.291-299, out. 2004. Disponível em: < http://www.revistas.usp.br/rbefe/article/ view/16674/18387 >. Acesso em: 12 fev. 2016.

PARLEBAS, Pierre. Juego deporte y sociedad: léxico de praxiologia motriz. Barcelona: Paidotribo, 2001.

SAMPIERI, Roberto Hernández; COLLADO, Carlos Fernández; LUCIO, María del Pilar Baptista. Metodologia de pesquisa. 5. ed. Porto Alegre: Penso, 2013. 624 p.

SÃO PAULO. Secretaria da Educação. Currículo do Estado de São Paulo: Linguagens, códigos e suas tecnologias/ Secretaria da Educação; coordenação geral, Maria Inês Fini; coordenação da área, Alice Vieira. - 2. ed. - São Paulo: SE, 2012. 260 p.

VAGO, Tarcísio Mauro. O "esporte na escola" e o "esporte da escola": da negação radical para uma relação de tensão permanente- Um diálogo com Valter Bracht. Movimento, Porto Alegre, v. 5, p.4-17, fev. 1996. Trimestral. Disponível em: < http://www.seer. ufrgs.br/index.php/Movimento/article/view/2228/936 > . Acesso em: 03 jul. 2016.

Recebido em: Julho/2017 Aprovado em: Outubro/2017 